\title{
The influence of classroom seating arrangement on children's cognitive processes in primary school: the role of individual variables
}

\author{
Valentina Tobia ${ }^{1}$ (]) $\cdot$ Simona Sacchi ${ }^{2}$ (D) $\cdot$ Veronica Cerina $^{3} \cdot$ Sara $^{\text {Manca }}{ }^{3} \cdot$ Ferdinando Fornara $^{3}$ (D) \\ Accepted: 28 October 2020 / Published online: 31 October 2020 \\ (C) Springer Science+Business Media, LLC, part of Springer Nature 2020
}

\begin{abstract}
To date, despite the great debate regarding the best seating arrangement for learning in classrooms, no empirical studies have examined the direct effects of different seating arrangements on children's cognitive processes. This is particularly important nowadays that the COVID-19 measures include maintaining distance in the classroom. Aim of this study was experimentally investigating the effect of changing the seating arrangement (clusters vs. single desks), on logical reasoning, creativity and theory of mind, in children attending primary school. Furthermore, some individual characteristics (e.g., gender, loneliness, popularity) were analysed as potential moderators. Results on 77 participants showed that, when children were seated in single desks, their score in logical reasoning was globally higher. Furthermore, when seated in single desks, girls showed a better performance in the theory of mind, and lonelier children performed better in theory of mind and creativity. This on field experimental study suggests the importance of considering both the nature of the task and children's individual characteristics when deciding on a seating arrangement in the classroom.
\end{abstract}

Keywords Primary school $\cdot$ Seating arrangement $\cdot$ Logical reasoning $\cdot$ Theory of mind $\cdot$ Creativity

A branch of research within environmental psychology focuses on the impact of learning environments, namely, schoolrelated structural and spatial dimensions, on students' outcomes in levels of achievement, engagement, affective state, attendance and well-being (Higgins, Hall, Wall, Woolner, \& McCaughey, 2005). Evidence from this field has shown that the physical environment of schools and classrooms has an important influence on students' comfort, on their behavior, and on social interactions among peers and between teachers and their students (Byers, Mahat, Liu, Knock, \& Imms, 2018; Wannarka \& Ruhl, 2008). Several studies have revealed that students' learning skills are also influenced by various environmental factors, such as school building design, noise, temperature, and lighting, as well as the presence of green spaces

Valentina Tobia

tobia.valentina@unisr.it

1 Faculty of Psychology, Vita-Salute San Raffaele University, Milan, Italy

2 Department of Psychology, University of Milano-Bicocca, Milan, Italy

3 Department of Education, Psychology, Philosophy, University of Cagliari, Cagliari, Italy
(Manca, Cerina, Tobia, Sacchi, \& Fornara, 2020). However, despite the current growing interest and considerable investment in school learning environments, empirical data that investigate how alternative spatial organizations of the learning environment directly impact children's cognitive processes are still lacking (Higgins et al., 2005). This issue is of major importance in the present days: following the massive closure of educational institutes around the world during the COVID19 emergence, school are re-opening, or are going to re-open, applying measures of social distancing (Fantini, Reno, Biserni, Savoia, \& Lanari, 2020; UNSESCO, 2020) that necessarily impact on classrooms' and schools' spatial organizations, in particular on seating arrangement.

\section{The Role of Seating Arrangement}

There is much debate in the educational field regarding the best seating arrangement in classrooms. In the traditional teacher-centered situation, the seating arrangement consists of rows and columns of single desks facing a blackboard, with the teacher's desk in front of the classroom. Alternatively, the student-centered approach allows students to work together and usually corresponds to the aggregation of desks (i.e., 
clusters). Both traditional seating in single desks and teachercentered approaches are the globally dominant approaches (Blackmore, Bateman, Loughlin, O'Mara, \& Loughlin, 2011), despite the fact that, in recent years, arrangement in clusters is becoming more frequent and preferred by teachers (Gremmen, van den Berg, Segers, \& Cillessen, 2016), providing a good basis for cooperative learning and other studentcentered approaches (Norazman, Ismail, Ja'afar, Khoiry, \& Ani, 2019).

Some studies have investigated student behavior and attainment based on seating arrangement and how seating arrangement affects the extent and nature of student interactions (Haghighi \& Jusan, 2012; van den Berg \& Cillessen, 2015). This branch of research has shown that behaviors connected to school tasks, such as hand-raising, asking questions, or being out of seat without permission, are associated with the arrangement of desks in the classroom (Wannarka \& Ruhl, 2008). Importantly, Wannarka and Ruhl's (2008) synthesis suggests that two elements should play a role in the decision of desk arrangement: the nature of the task administered and children's individual characteristics. Being seated in rows makes interactions among peers inconvenient and apparent to teachers; thus, this organization is superior to minimize disruptive behavior and maximize on-task behavior during individual activities (Wannarka \& Ruhl, 2008). Considering individual characteristics, it was found that disruptive students and children with poor attention-characteristics associated with low popularity among classmates (Newcomb, Bukowski, \& Pattee, 1993) — seem to benefit the most from the seating arrangement involving rows and columns of single desks (Hastings \& Schwieso, 1995). Also, gender differences in the attitude toward seating arrangement has been found, despite only for college students (Burgess \& Kaya, 2007): females were more at ease than males in the in the rows of tablet-arm chairs and in the cluster layouts, and males had slightly lower social interaction scores than females regardless of the classroom layout.

As described above, classroom arrangement significantly influences students' behavior (Wannarka \& Ruhl, 2008); in addition, it has been hypothesized that classroom arrangement impacts achievement (Cheryan, Ziegler, Plaut, \& Meltzoff, 2014; Pace \& Price, 2005). However, to date, no studies have empirically investigated how the more common seating arrangements directly influence cognitive processes in schoolage children. An exception is a study by Bennett and Blundell (1983) that analyzed the effect of row vs. cluster seating arrangements on the quantity and quality of the work produced in reading, language and mathematics in primary school children. They found that the quantity of work completed increased when children were seated in rows, while the quality of work was maintained. To date and to the best of our knowledge, this is the only study that has experimentally investigated this issue.
Insights into the influential role that seating arrangement can have on students' cognitive performance derived from studies investigating learning skills in association with the habitual seating location of an individual in the classroom (Marshall \& Losonczy-Marshall, 2010; Perkins \& Wieman, 2005). In one of these studies, Pichierri and Guido (2016) longitudinally followed five marketing classes attended by young adults, exploring students' achievement in terms of grades. They found that students in the front rows achieved the highest grades and that the individuals' levels of shyness moderated the relationship between achievement and position. This last result supports the value of considering student characteristics as potential moderators of the effects of classroom seating arrangement on performance. However, although these studies shed light on the relationship between habitual seating position and school achievement, they do not directly support the existence of a causal influence of the first on the second because, for example, the seating positions are usually chosen by teachers for younger students and chosen by students themselves from adolescence. Thus, many factors related to achievement can be directly implicated in this choice (e.g., teachers choose the student seating positions based on their ability and cognitive skills; Gremmen et al., 2016).

Therefore, despite the literature offering some suggestions, we still do not know whether and how the more common seating arrangements directly influence cognitive and learning processes in school-age children. This information is particularly important for the current debate on the best seating arrangement in classrooms. Additionally, the majority of the research on the effects of school learning environments on student behavior and learning did not consider a fundamental component of this potential association, that is, students' individual variables. Finally, a central question remains poorly addressed: why would seating arrangement influence cognitive processes?

\section{Interpersonal Distance as a Framework for Understanding the Effects of Seating Arrangement in the Classroom}

A possible theoretical framework for explaining how different seating arrangements within the classroom impact children's cognitive processes is the construct of interpersonal distance. The desk arrangement within the classroom is linked, on the one hand, to the possibility of movement and interactions among peers and with the teacher and, on the other hand, to the interpersonal distance between individuals. For example, the traditional row and column seating arrangement places students relatively far away from each other, compared to the cluster or "horseshoe" arrangements. Interpersonal distance is a classical construct in social psychology (Felipe \& Sommer, 1966; Sundstrum \& Altman, 1976), and it is known 
to influence both relational and cognitive processes (Amit, Wakslak, \& Trope, 2012). However, interpersonal distance does not affect every individual in the same manner: its influence is connected to specific variables, such as personality characteristics (e.g., some individuals perceive proximity as an invasion of personal space; Kaitz, Bar-Haim, Lehrer, \& Grossman, 2004), gender (e.g., females tend to stay closer compared to males; Costa, 2010; Maccoby, 1990) and the existing relationships among individuals (Mehrabian, 1968).

A few studies have directly analyzed the influence of interpersonal distance on cognitive tasks. For example, it was shown that interpersonal distance influences spatial attention, moving such attention away from the close individual, but only when both participants were performing the exact same task (Szpak, Nicholls, Thomas, Laham, \& Loetscher, 2016). A similar negative influence of closeness on other cognitive tasks was also found by older studies (Nagar \& Pandey, 1987) that involved convergent thinking (Guilford, 1956). Studies on a school's space density and its effects on the achievement of adults and children can offer further information, considering the link between space density and interpersonal distance among individuals within a space (Rüstemli, 1992). This line of research showed, for example, that student's academic achievement (i.e., word reading) was negatively influenced by less space in the classroom, particularly for girls (Maxwell, 2003), revealing the moderating role of gender. Interpersonal distance also plays a role in influencing other cognitive tasks, such as tasks involving divergent thinking (e.g., creativity; Lamm \& Trommsdorff, 1973) or components of social cognition (e.g., empathy; Strayer \& Roberts, 1997).

Different underlying mechanisms are likely to explain the effects of interpersonal distance on the cognitive performance. A possible explanation for its detrimental effects comes from the social discomfort hypothesis (Aiello, 1987), positing that stress-related responses are experienced when others invade our personal space. Recovering from stress is highly demanding in terms of cognitive resources, which can be less available for solving cognitive tasks (e.g., Helton, Matthews, \& Warm, 2009). For example, prior studies on the effects of physical environment on creativity (see Meinel, Maier, Wagner, \& Voigt, 2017) showed that, whereas social interactions and proximity would promote team creativity (Milliken, Bartel, \& Kurtzberg, 2003; Paulus \& Yang, 2000), individual creativity is likely to be fostered by privacy (Dul \& Ceylan, $2011,2014)$ and by the sense of freedom from social and physical constraints (e.g., Steidle \& Werth, 2013). Considering social cognition, characters who elicited greater empathy also elicited closer interpersonal distances. For this variable, the link with interpersonal distance has been hypothesized to be the consequence of an active sharing of another person's experience (Strayer \& Roberts, 1997).

As noted by van den Berg and colleagues (van den Berg, Segers, \& Cillessen, 2012), it is surprising that distance in the classroom has been so rarely considered a factor in school functioning, despite children spending many hours in this environment. The present study aims to fill this gap by examining how cognitive processes are influenced by interpersonal distance among classmates, manipulated by the changing of their seating arrangement.

\section{Aims of the Study}

Based on the aforementioned literature, it can be hypothesized that cognitive processes can be directly influenced, namely, improved or worsen, by the classroom seating arrangement. Furthermore, considering past research on behavior based on students' seating arrangement (Wannarka \& Ruhl, 2008) and on the effects of interpersonal distance on cognitive tasks (e.g., Maxwell, 2003), it is plausible to expect an influence on cognitive processes that also depends on specific individual variables, which can play the role of either protective factors or risk factors, and on task characteristics. To date, despite the great debate regarding the best seating arrangement for learning in classrooms, no empirical studies have examined these issues. Furthermore, considering the COVID-19 related measures on social distancing impacting on classrooms' spaces, studying the effects of seating arrangements on children's performance is particularly urgent. Thus, the present study aims to experimentally investigate the effects of two classroom seating arrangements, clusters and single desks, on children's different cognitive processes: convergent thinking (logical reasoning), divergent thinking (creativity) (Guilford, 1956), and social cognition (theory of mind ToM; Baron-Cohen, Wheelwright, Spong, Scahill, \& Lawson, 2001). Moreover, the influence of children's individual variables, which, in previous studies, showed a link with cognitive performance or a relation with interpersonal distance or seating arrangement, was explored: gender (Burgess \& Kaya, 2007; Maxwell, 2003), relational self-esteem (Burnett, 1998), popularity (van den Berg \& Cillessen, 2015), loneliness (Cacioppo \& Hawkley, 2009), and physiological reaction to proximity (Lipsitz \& Schneier, 2000).

The first hypothesis of this study is to find a poorer performance in the logical reasoning and creativity tasks when children were seated in clusters (smaller interpersonal distance), in line with previous results that showed a negative effect of closeness among individuals on tasks involving convergent thinking (Szpak et al., 2016) and divergent thinking (Lamm \& Trommsdorff, 1973), although the literature has shown mixed results concerning divergent thinking (Milliken et al., 2003). Considering social cognition, a previous study that investigated the link between interpersonal closeness and empathy showed a positive association (Strayer \& Roberts, 1997). However, a different social cognition component was used in the present study (i.e., ToM); therefore, the 
investigation of how seating arrangement influences ToM was explorative. Furthermore, it could be hypothesized that the effects of seating arrangement on the cognitive tasks considered would be moderated by children's gender, their relational self-esteem, their popularity and loneliness within the class group and their physiological reaction to proximity as a measure of social anxiety. In particular, male and less socially competent pupils would be more negatively affected by social proximity than females and socially competent individuals (i.e., more popular and less alone, higher relational self-esteem, lower physiological reaction to proximity), in line with past studies showing a greater tolerance of proximity, and better outcomes when close to other people, in these populations (e.g., Burgess \& Kaya, 2007; Kaitz et al., 2004).

\section{Method}

\section{Participants}

An a priori power analysis was conducted for sample size estimation (using G*Power 3.1; Faul, Erdfelder, Lang, \& Buchner, 2007). With an $\alpha=.05$ and power $=.80$, the projected sample size needed to detect a medium effect size $\left(f^{2}=.15\right)$ for a regression with three predictors (the independent variable, the individual variable and their interaction) is $\mathrm{N}=77$. A letter presenting the study had been sent to the parents of children attending 5 primary school classes, and 78 of the parents gave their consent for participation. One participant with a diagnosis of cognitive disability was excluded from the analysis. The final sample included 77 children $(57.1 \%$ girls; age range $=8$ 11 years, mean age $=9.59$ years, $\mathrm{SD}=.66$ years) attending a primary school in Northern Italy. Three $4^{\text {th }}$ and two $5^{\text {th }}$ grades classes were involved in the study. In three classes $(n=46)$ the desks were usually arranged in rows, whereas in the remaining two classes $(n=31)$ children were usually seated in couples. Therefore, both the classrooms' usual arrangements were different from the arrangements used as manipulations.

\section{Materials and Procedure}

The experiment was conducted in accordance with the guidelines defined by the Declaration of Helsinki and it has been approved by the local ethics committee. The tasks were administered over three sessions at the children's school, within school hours. During the first phase (T0), a questionnaire was collectively administered in the children's classroom in a 1-h session, investigating the following variables:

Relational Self-Esteem The Social Subscale from the Italian adaptation of the Multidimensional Self-Concept Scale (Bracken, 2003) was administered. The subscale includes 25 sentences (e.g., "I have many friends"), and each sentence is scored from 1 (strongly disagree) to 4 (strongly agree). The mean score was calculated $(\alpha=0.87)$.

Peer Ratings A peer rating questionnaire was administered. Children were asked to rate each classmate from 0 (not at all) to 3 (very much) in relation to two situations investigating popularity ("You go to the mountains for the weekend, and your mom tells you that you can bring a friend with you. How would you like to invite your classmates?") and loneliness ("Some children are often alone in the classroom, have only a few friends and do not play much with other children. How much each of your classmates is similar to this description?"). This instrument was developed ad-hoc for this study, based on similar instruments used by other studies that have investigated peer relationships within schools (e.g., Tobia, Riva, \& Caprin, 2017). For all the children, a score for each variable was obtained by calculating the mean rating given by the classmates.

Physiological Reaction to Proximity Children completed a scale adapted from the Brief Social Phobia Scale (Davidson et al., 1991), asking, on a 5-point Likert scale ( 1 = never and 5 = always), how frequently they experience some physiological reactions (e.g., blushing and sweating) during interpersonal proximity. Four items were included in the scale, and the mean score was calculated $(\alpha=0.63)$.

Approximately two weeks after T0, the first experimental manipulation (T1) was administered within each classroom: for 3 randomly selected classes, desks were arranged in clusters of four children each, ${ }^{1}$ and for the remaining 2 classes, desks were arranged in single desks (see Fig. 1a,b). This last arrangement is in line with the last guidelines for school reopening in Italy, pointing out the need of single isolated desks (MIUR, 2020). Maintaining this arrangement, children were asked to complete a series of cognitive tasks. One week later, a beta version of the same tasks was administered after organizing the classroom with the alternative seating arrangement (T2). An experimental design using a within-participants single factor with two levels (desk arrangement: clusters vs. single desks) was therefore adopted and order was properly balanced.

The cognitive tasks administered in the two experimental sessions were as follows:

Logical Reasoning A selection of 30 items from the K-BIT 2 Matrices subtest (Kaufman \& Kaufman, 2004; $\alpha=.84$ ) was presented. This task requires the understanding of the relationships among visual stimuli and assesses reasoning in its nonverbal form. For creating the alpha and beta versions of this task, the 30 items were divided into two 15-item sets, each

\footnotetext{
${ }^{1}$ When, due to the total number of children in the classroom, this was not possible, one or two clusters of 3 or 5 were allowed.
} 
Fig. 1 Seating arrangements used for the experimental manipulation: desks were arranged in (a) clusters or in (b) single desks (a)

(b)
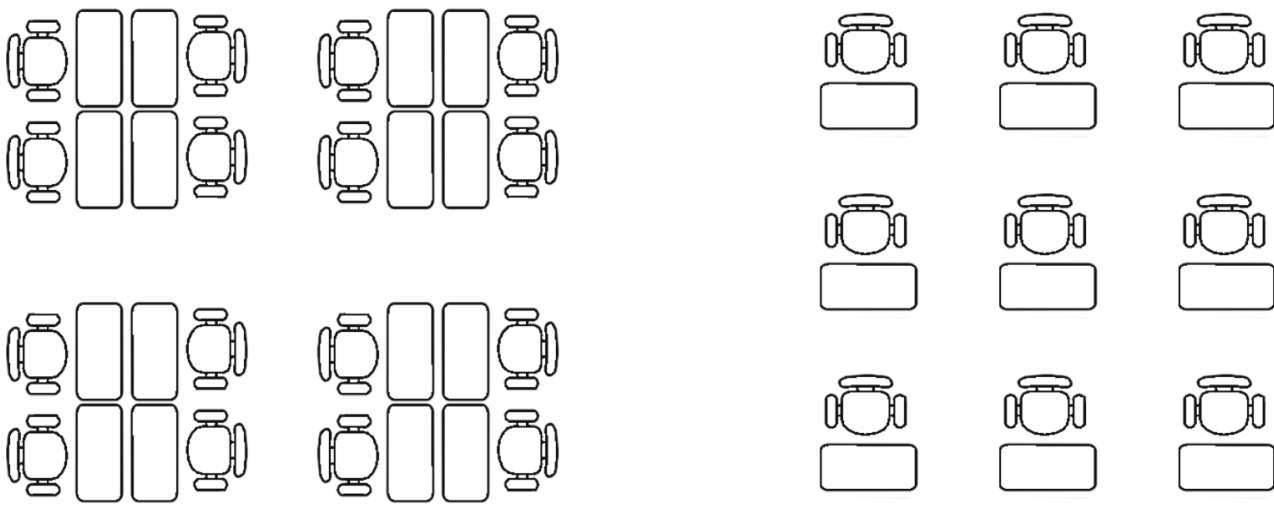

used in one of the sessions. The number of correct responses was considered.

Creativity The Alternative Uses Task (Guilford, 1967) was administered. Children were asked to imagine new uses for two familiar objects (one for each session): a brick and a clothes hanger. They were instructed to list as many ideas as possible, and the number of ideas produced by each child was recorded. Furthermore, the originality of the proposed objects' uses was assessed by two blind judges, who rated each idea on a 5-point scale (the mean score was considered).

Theory of Mind (ToM) Participants completed the child's version of the Reading the Mind in the Eyes Test (Baron-Cohen et al., 2001). This task includes 28 pictures of the eye area of the face, and the child is asked to pick which of four words best describes what the person in the photo is thinking or feeling. Alternatives can be affective (e.g., angry) and nonaffective (cognitive; e.g., is remembering) mental state terms, and only one is correct. For creating the alpha and beta versions of this task, the 28 items were divided into two 14item sets, each used in one of the sessions. The number of correct responses was considered.

At the end of the second session, participants were properly debriefed.

\section{Data Analysis}

A set of independent t-tests was preliminarily run in order to explore possible differences in the dependent variables (logical reasoning, creativity and theory of mind) based on children's usual seating arrangement. Then, a two-condition within-participants design was implemented, with the experimental manipulation of the arrangement (clusters vs. single desks) as a within factor. A series of 2 (arrangement: clusters vs. single desks) x2 (gender: girl vs. boy) ANOVAs were run to investigate the effects of the experimental manipulation and children's gender on tasks performance. Then, the MEdiation and MOderation analysis for REpeated measures design (MEMORE; Montoya \& Hayes, 2017) macro was used to estimate the effects of the experimental manipulation $(0=$ single desks; 1 = clusters) on the dependent variables (Y), considering the influence of a continuous moderator (M). The dependent variables investigated were logical reasoning, creativity and theory of mind. The moderators were relational self-esteem, popularity, loneliness, and physiological reaction to proximity. With these analyses we investigated if the impact of the seating arrangement on the dependent variables is the same for all individuals or change in function of different levels of relational self-esteem, popularity, loneliness, or physiological reaction to proximity (moderators) showed by participants.

\section{Results}

\section{Preliminary Analysis}

The set of t-tests run for investigating possible differences in logical reasoning, creativity and theory of mind measured when children were seated in single desks or in clusters, based on children's usual seating arrangement, showed no significant results, $t(75)=-.952-1.729, p=.088-.809$. Usual seating arrangement was therefore excluded from the following analysis.

\section{Descriptive Statistics}

The descriptive statistics for the individual characteristics considered as potential moderators are presented in Table 1, together with the correlations among them. The descriptive statistics of the results of the cognitive tests administered when children were arranged in clusters or in single desks are reported in Table 2. 
Table 1 Descriptives for the individual variables measured as potential moderators and Pearson correlations among them

\begin{tabular}{llllll}
\hline Variable & Mean (SD) & Min-Max & Peer ratings: popularity & Peer ratings: loneliness & Physiological reaction scale \\
\hline Relational self-esteem & $3.10(.39)$ & $1.92-3.76$ & .176 & $-.469^{* *}$ & -.161 \\
Peer ratings - popularity & $1.58(.43)$ & $.55-2.46$ & & $-.423^{* *}$ & .148 \\
Peer ratings - loneliness & $.61(.46)$ & $0-2$ & & .084 \\
Physiological reaction scale & $2.15(.87)$ & $1-4.25$ & & & \\
\hline
\end{tabular}

Note. $\mathrm{SD}=$ standard deviation

$* * p<.01$

\section{Role of Gender}

To explore the role of gender, a series of 2 (arrangement: clusters vs. single desks) x 2 (gender: girl vs. boy) ANOVAs was carried out on the tasks' scores. The analysis performed on logical reasoning as the dependent variable showed a significant main effect of arrangement, $F(1,75)=4.486$, $p=.037, \eta^{2}=.056$, with higher scores observed in the row and column condition. In contrast, both the effects of gender, $F(1$, $75)=.007, p=.933$, and of the interaction between gender and arrangement, $F(1,75)=1.676, p=.199$, were nonsignificant. A significant interaction between gender and arrangement was found for the ToM task, $F(1,75)=4.208, p=.044, \eta^{2}=.053$. Pairwise comparisons of the marginal estimates showed that girls obtained significantly higher scores $(p=.013, d=.48)$ when they were arranged in single desks compared to the clustered arrangement. In contrast, boys obtained similar ToM scores in the two conditions $(p=.605)$. Both the main effects of arrangement and gender were nonsignificant, $F(1,75)=1.605, p=.209$ and $F(1,75)=.025, p=.875$, respectively. Finally, the analysis run on creativity did not yield significant main or interaction effects, $F(1,75)=.005-.483, p=.489-.944$.

\section{Moderation Analysis}

To investigate the role of relational self-esteem, popularity, loneliness and physiological reaction to proximity in the relationship between seating arrangement and logical reasoning,

Table 2 Descriptives of the cognitive tests administered when children were arranged in clusters or in single desks

\begin{tabular}{|c|c|c|c|c|}
\hline \multirow[t]{2}{*}{ Variable } & \multicolumn{2}{|l|}{ Clusters } & \multicolumn{2}{|l|}{ Single desks } \\
\hline & Mean (SD) & Min-Max & Mean (SD) & $\begin{array}{l}\text { Min- } \\
\text { Max }\end{array}$ \\
\hline Logical reasoning & $10.96(2.43)$ & $5-15$ & $11.47(2.67)$ & $4-15$ \\
\hline Creativity: $\mathrm{n}^{\circ}$ ideas & $3.30(2.10)$ & $0-9$ & $3.09(1.95)$ & $0-8$ \\
\hline $\begin{array}{l}\text { Creativity: } \\
\text { originality }\end{array}$ & $2.85(.49)$ & $1.50-4.50$ & $2.97(.56)$ & $2-4.50$ \\
\hline Theory of mind & $7.97(2.13)$ & $3-13$ & $8.46(2.25)$ & $2-13$ \\
\hline
\end{tabular}

Note. $\mathrm{SD}=$ standard deviation creativity and theory of mind, a series of moderation analyses were run. The results revealed that relational self-esteem, popularity, and physiological reactions to proximity were not significant moderators of the effects of the seating arrangement on the cognitive variables considered, $F(1,75)=.001-2.756$, $p=.101-.977$.

However, the impact of the seating arrangement on creativity depends on the levels of loneliness as rated by peers, both considering the measure of the number of ideas, $F(1,75)=6.368, p=.014$, and their originality, $F(1,61)=6.948$, $p=.011$. As represented in Fig. 2, children with a loneliness score lower than 0.33 , which included $32.47 \%$ of the participants, presented more ideas in the creativity task when they were seated in clusters; conversely, children with a loneliness score higher than 1.65 , representing the lonelier $5.19 \%$ of the sample, had a better performance when seated in single desks. Considering the originality of these ideas (Fig. 3), children with a loneliness score higher than 0.88 , corresponding to $19.05 \%$ of the sample, presented more original ideas when they were seated separately in single desks.

In addition, loneliness played a significant role in moderating the effect of the experimental manipulation on ToM, $F(1,75)=4.367, p=.040$. In particular, the seating arrangement significantly impacted the performance of children with a loneliness score higher than 0.71 (Fig. 4), which corresponded to the lonelier $28 \%$ of participants, for whom theory of mind score was significantly lower when working in clusters. Considering the interaction of gender $\mathrm{x}$ arrangement found in the previous analysis, a chi-square test was performed to check the gender distribution in the two groups of children with a loneliness score higher and lower than 0.71 . The results indicated a similar distribution of boys and girls in the two groups, $\chi 2(1)=.530, p=.466$. Thus, given the lack of association between gender and loneliness scores, gender difference seems to not affect the moderating role of loneliness.

\section{Discussion}

The goal of this on field study was to determine the effect of an experimental manipulation of classroom seating arrangement on different types of cognitive tasks, in children 
Fig. 2 Moderation graph describing the effect of seating arrangement on number of ideas in the creativity task (ordinate), based on children's loneliness as rated by peers (abscissa); children with a loneliness score lower than 0.33 and higher than 1.65 were significantly affected by the manipulation. $\mathrm{NS}=$ non significant.

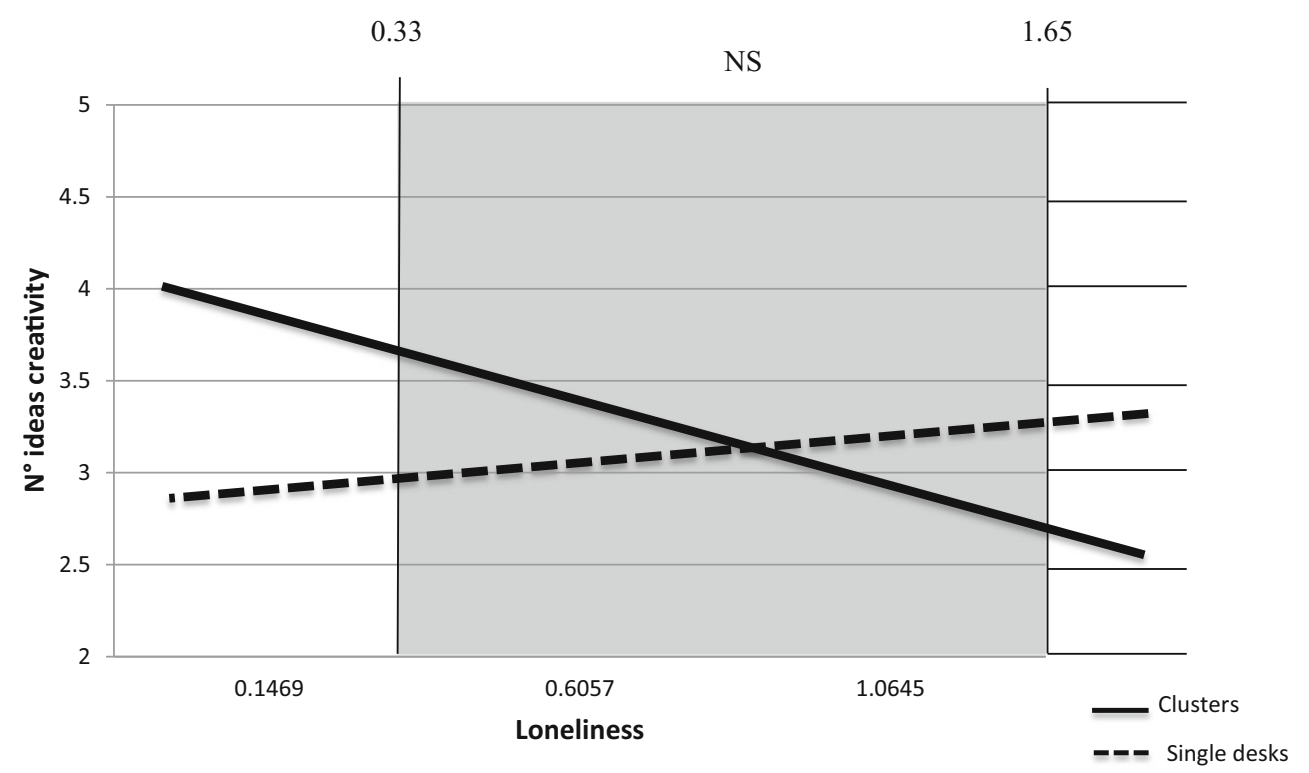

attending primary school. In particular, the effect of seating arrangement in relation to some individual characteristics was analyzed: gender, relational self-esteem, popularity and loneliness as assessed by classmates, and physiological reaction to proximity were the moderators considered. The cognitive tasks included as outcomes involved convergent thinking (logical reasoning), divergent thinking (creativity), and social cognition (theory of mind). One of the tested seating arrangements (i.e., single desks) is the arrangement prescribed by the last guidelines for school re-opening in Italy (MIUR, 2020), for ensuring social distancing as a measure against COVID19. This makes the results of the present study a peculiar window on the current time.

The results indicated that the logical reasoning performance was higher when children were positioned at a greater distance from one another, which is the single desks seating arrangement. The main effect of the experimental manipulation found for the logical reasoning task is partially in line with the limited previous literature that has shown that children are more able to solve individual tasks when seated in single desks (Bennett \& Blundell, 1983). While Bennett and Blundell's study showed that being seated separately from peers positively influenced the quantity of work that children were able to complete, the present study suggests that quality, in terms of correct responses, is also promoted. However, the nonsignificant main effect that emerged for the other cognitive tasks suggests that seating arrangement influences cognitive performance in different ways. Although this was the only significant main effect of the experimental manipulation that emerged, further significant results were observed when considering individual variables as moderators.
Fig. 3 Moderation graph describing the effect of seating arrangement on the originality of ideas in the creativity task (ordinate), based on children's loneliness as rated by peers (abscissa); children with a loneliness score higher than 0.88 were significantly affected by the manipulation. $\mathrm{NS}=$ non significant

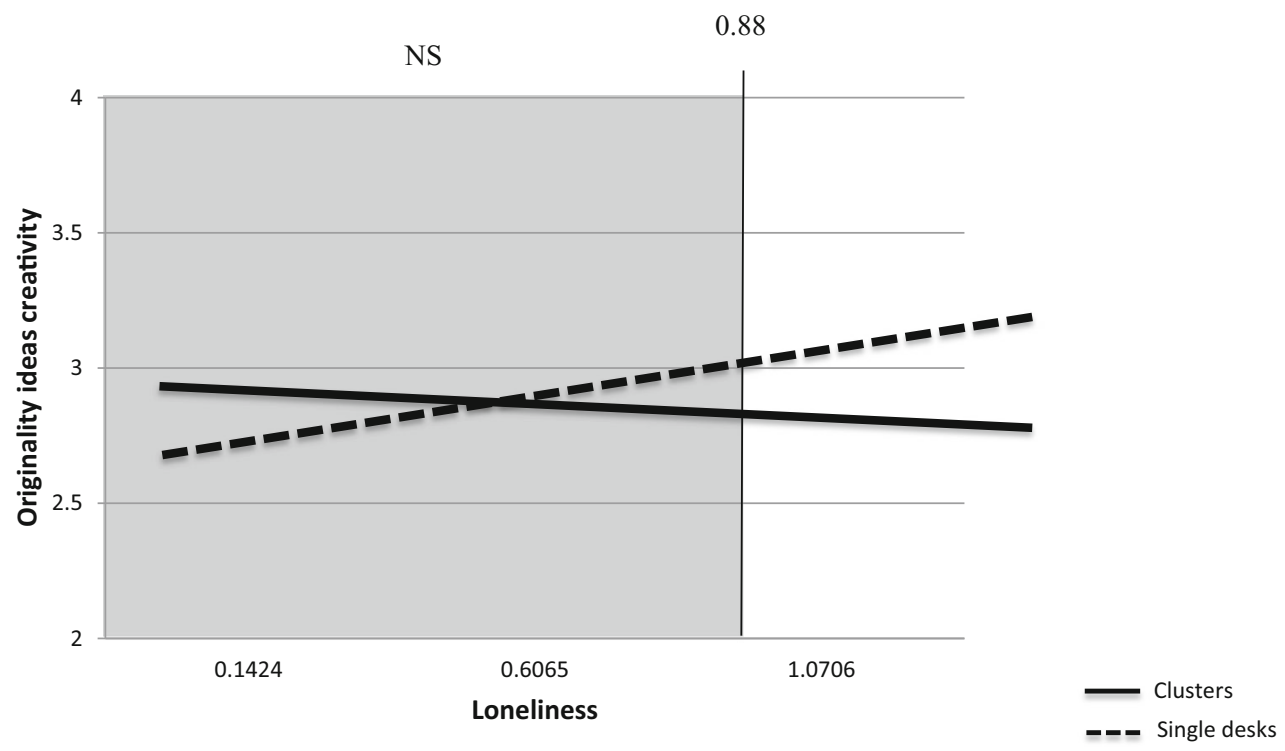


Fig. 4 Moderation graph describing the effect of seating arrangement on the theory of mind (ordinate), based on children's loneliness as rated by peers (abscissa); children with a loneliness score higher than 0.71 were significantly affected by the manipulation. $\mathrm{NS}=$ non significant.

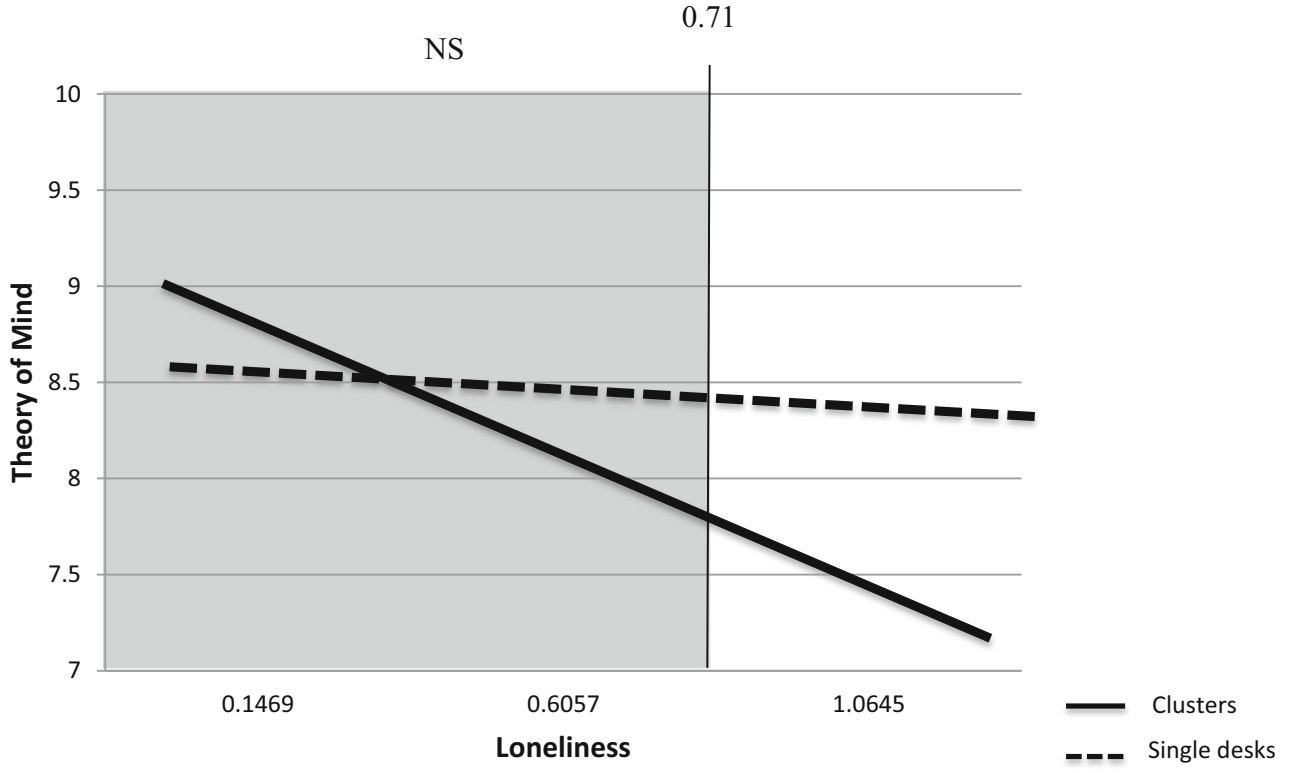

\section{Moderating Role of Gender}

The first moderator that showed a significant influence on the effect of seating disposition on a cognitive task was gender: girls showed better performance in the social cognition (i.e., ToM) task when seated separately. A possible explanation for this result is related to the different nature of social competence found in girls and boys, with girls showing more nurturance and concern with social issues (Rose-Krasnor, 1997) and better emotion recognition skills (McClure, 2000) than boys. It can be hypothesized that girls, compared to boys, are more attentive to peers when they are close to them, which leads their attention and cognitive resources away from the cognitive task that they are working on. This hypothesis would be particularly true when children are involved in a social cognition task, leading their attention to social cues. Therefore, close peers would act as irrelevant environmental stimuli for girls, competing with the ToM task stimuli and leading to a major cognitive load and consequently weaker performance (Choi, Van Merriënboer, \& Paas, 2014).

\section{Moderating Role of Loneliness}

The stronger result of the present study was the role played as a moderator by children's level of loneliness. It moderated the effect of the seating arrangement on the ToM performance: lonelier children performed better in the social cognition task when seated in single desks. Loneliness, as assessed by peers, also moderated the effect of seating arrangement on the creativity task: the lonelier children were able to think of a greater number of ideas when seated separated in single desks, whereas the children in the one-third of the sample that felt less alone had more creative ideas when seated in clusters. Finally, the originality of these ideas was influenced by seating arrangement for the lonelier children, which had a higher originality score when seated separated by classmates (i.e., single desks).

According to the model of loneliness proposed by Hawkley and Cacioppo (2010), lonely individuals show hypervigilance for social threats, which exerts a powerful influence on perceptions and cognition, leading to overattention to negative social information in the environment and less resources for other tasks. It is possible that this mechanism is stronger when lonely children are close to peers: having classmates close to them would move their attention to this social cue, resulting in more cognitive load (Choi et al., 2014) and less attention to the requested task. Similarly, being close to peers can lead, for some individuals, to the need for self-regulation skills, for example, to regulate levels of anxiety and fear of rejection. Self-regulation implies the activation of frontal brain areas (Rothbart, Sheese, Rueda, \& Posner, 2011), which is also associated with the executive functions and higher-order cognitive processes needed for solving cognitive tasks (Diamond, 2013). Accordingly, loneliness has been associated with impaired cognitive performance and cognitive decline over time (Cacioppo \& Hawkley, 2009). For the creativity task, a significant moderation effect was also obtained for children with low levels of loneliness, who were able to think of a greater number of ideas when seated in clusters. Therefore, children less frequently used to being alone benefitted from the closeness of peers in a task involving divergent thinking. This result is in line with previous studies that showed better functioning in creative tasks when working and interacting in groups (Milliken et al., 2003; Paulus \& Yang, 2000), although in this case, children were required to solve individual tasks in a clustered disposition. However, cluster arrangement is related to cooperative learning and other student-centered approaches in the school daily life (Norazman et al., 2019), so less alone students could symbolically perceive the situation as a "group work", benefiting from 
its positive consequences on a creative task. This result suggests that the mere physical proximity can lead to the benefits that group work provides for creative thinking.

\section{Nonsignificant Moderators}

Considering the significant effect of loneliness as a moderator, an opposite pattern of results (i.e., with stronger performance in cognitive tasks for popular children when seated in clusters) for popularity was expected. This is because lonelier children are usually less popular, and vice versa (Newcomb et al., 1993). In contrast, popularity was not a significant moderator of the experimental manipulation. A possible reason for this result is that the link between popularity and loneliness is not as straightforward. Popularity is defined as the degree to which a child is liked by the peer group (Newcomb et al., 1993); this variable has been shown to exert an indirect influence on loneliness through its effects on other variables, such as feelings of belongingness (Bukowski, Hoza, \& Boivin, 1993). In line with this observation, the correlation between these two peer rating variables was only moderate. Popularity in children is associated with smaller interpersonal distance: peers like popular children and usually seek to be closer to them (van den Berg \& Cillessen, 2015). On the other hand, it has been shown that popular children can sometimes be dominant and aggressive, particularly relationally aggressive (Lease, Kennedy, \& Axelrod, 2002), and therefore, some children might want to maintain distance from them. These mixed results regarding popularity and preferred interpersonal distance - associated to seating arrangement - can be the reason for the nonsignificant moderating effect of popularity.

Additionally, neither relational self-esteem nor physiological reaction to proximity were moderators of the effects of seating arrangement, despite both being variables that are closely linked to the experience of social closeness. However, the lack of results regarding these variables can be the consequence of the instrument used to assess them. First, the reliability score for the scale assessing physiological reaction to proximity was not adequate, and this could have affected, at least partially, the results regarding this moderator. Then, it has been shown that children may struggle to describe their experience via a self-report measure (Varni, Limbers, \& Burwinkle, 2007). In the present study, peer-rated (i.e., loneliness) or objective (i.e., gender) measures, more than selfreported measures, were significant moderators. The use of multiple points of view for assessing potential moderators could help to better investigate the effects of these variables.

\section{Implications}

The present study suggests the importance of considering both the nature of the task and children's individual characteristics when deciding on a seating arrangement in the classroom. In particular, teachers should prefer a seating arrangement that keeps students separated when working on tasks involving convergent thinking, such as reasoning tasks. Considering students' characteristics, teachers should pay attention when children who are usually alone work close to classmates (i.e., seated in clusters) because this closeness could impair their cognitive performance for some types of tasks. Accordingly, school policies aimed at consolidating the group class and leading all children to be socially integrated with classmates would be helpful.

Furthermore, these results have implications for the definition of the architecture and design of learning environments. Flexible learning spaces and mobile furniture for classrooms that allow for the quick rearrangement of the room (Neill \& Etheridge, 2008) are recommended because seating patterns need to be consistent with learning aims. This type of furniture would allow for the arranging of both traditional and studentcentered classroom environments, based on the type of task and on the students involved.

Finally, these results suggest that the seating arrangement recommended by the guidelines of social distancing for COVID-19 could have a positive impact on some types of tasks and for some types of students. However, to better respond to all classmates' needs and to didactic needs, these measures should be maintained only for the time necessary to the sanitary emergence, and abandoned immediately after, in order to allow the flexibility in the organization of classrooms' spaces.

\section{Conclusions and Future Directions}

The present study showed that changes to the traditional school learning environment (i.e., the row and column seating arrangement) toward a student-centered approach (i.e., cluster seating arrangement) did not always correlate with positive effects on academic achievement (Byers et al., 2018). In contrast, for some tasks and for some individuals, a larger interpersonal distance from classmates can be an environmental factor leading to better performance in cognitive tasks. Teachers should consider both the nature of the learning tasks and the characteristics of the children when organizing seating arrangements in primary school classrooms.

This on field study is one of the first studies to experimentally investigate the effects of classroom seating arrangements on students' cognitive performance, additionally considering individual variables as potential moderators. Future studies with similar methodologies are needed to explore the effects of seating arrangements on other cognitive tasks and, beyond the performance, on the learning process. Further research might also identify other individual (e.g., rejection sensitivity; Downey, Lebolt, Rincón, \& Freitas, 1998) and contextual (e.g., relationship with classmates, gender of the close classmate) factors that can serve as moderators. 
Moreover, children and adolescents of different ages should be involved in similar research to verify whether individual variables play a different role based on students' developmental stage.

Also, the present study proved the effects of a short-term manipulation on cognitive tasks administered during this manipulation. However, the effects of the seating arrangement could be more pervasive if a specific arrangement of desks is maintained daily for weeks or even months; alternatively, the effects could decrease when a specific position in the classroom becomes a habit. Future studies could implement long-term manipulations of seating arrangement, in order to analyze if their cognitive effects remain stable over time.

Funding This study was financially supported by the Iscol@ Project (Autonomous Region of Sardinia, Italy, Regional Council Deliberation n. $10 / 15,28 / 03 / 2014)$

Data Availability The datasets generated during and/or analysed during the current study are available from the corresponding author on reasonable request.

\section{Compliance with Ethical Standards}

Conflict of Interest The authors declare that they have no conflict of interest.

Ethics Approval Approval was obtained from the ethics committee of the University of Milan-Bicocca. The procedures used in this study adhere to the tenets of the Declaration of Helsinki.

Consent to Participate Written informed consent was obtained from the parents.

\section{References}

Aiello, J. R. (1987). Human spatial behavior. Handbook of Environmental Psychology, 1, 389-504.

Amit, E., Wakslak, C., \& Trope, Y. (2012). The use of visual and verbal means of communication across psychological distance. Personality and Social Psychology Bulletin, 39, 43-56. https://doi.org/10.1177/ 0146167212460282

Baron-Cohen, S., Wheelwright, S., Spong, A., Scahill, V., \& Lawson, J. (2001). Studies of theory of mind: Are intuitive physics and intuitive psychology independent. The Core Deficit in Autism and Disorders of Relating and Communicating, 5, 47-78.

Bennett, N., \& Blundell, D. (1983). Quantity and quality of work in rows and classroom groups. Educational Psychology, 3(2), 93-105. https://doi.org/10.1080/0144341830030201.

Blackmore, J., Bateman, D., Loughlin, J., O’Mara, J., \& Loughlin, J. (2011). Research into the connection between built learning spaces and student outcomes: Literature review. Melbourne: Victorian Department of Education and Early Childhood Development. Retrieved from http://www.education.vic.gov.au/Documents/ about/programs/infrastructure/ blackmorelearningspaces.Pdf.

Bracken, B. A. (2003). TMA. Test di Valutazione Multidimensionale dell'Autostima [TMA. Test for the multidimensional evaluation of self-esteem]. Trento: Erickson Editions.
Bukowski, W. M., Hoza, B., \& Boivin, M. (1993). Popularity, friendship, and emotional adjustment during adolescence. In B. Laursen (Vol. Ed.) and W. Damon (Series Ed.), New directions for child development: No. 60. Close friendships in adolescence (pp. 23-37). San Francisco: Jossey-Bass.

Burgess, B., \& Kaya, N. (2007). Gender differences in student attitude for seating layout in college classrooms. College Student Journal, 41(4), 940-947.

Burnett, P. C. (1998). Measuring behavioral indicators of self-esteem in the classroom. Journal of Humanistic Education \& Development, 37, 107-114. https://doi.org/10.1002/j.2164-4683.1998.tb00412.x.

Byers, T., Mahat, M., Liu, K., Knock, A., \& Imms, W. (2018). Systematic review of the effects of learning environments on student learning outcomes. Melbourne: University of Melbourne, LEaRN Retrieved from: http://www.iletc.com.au/publications/reports.

Cacioppo, J. T., \& Hawkley, L. C. (2009). Perceived social isolation and cognition. Trends in Cognitive Sciences, 13(10), 447-454. https:// doi.org/10.1016/j.tics.2009.06.005.

Cheryan, S., Ziegler, S. A., Plaut, V. C., \& Meltzoff, A. N. (2014). Designing classrooms to maximize student achievement. Policy Insights From the Behavioral and Brain Sciences, 1(1), 4-12. https://doi.org/10.1177/2372732214548677.

Choi, H. H., Van Merriënboer, J. J., \& Paas, F. (2014). Effects of the physical environment on cognitive load and learning: Towards a new model of cognitive load. Educational Psychology Review, 26(2), 225-244. https://doi.org/10.1007/s10648-014-9262-6.

Costa, M. (2010). Interpersonal distances in group walking. Journal of Nonverbal Behavior, 34(1), 15-26.

Davidson, J. R., Potts, N. L., Richichi, E. A., Ford, S. M., Krishnan, K. R., Smith, R. D., \& Wilson, W. (1991). The brief social phobia scale. The Journal of Clinical Psychiatry, 52, 48-51. https://doi.org/10. 1037/t07672-000.

Diamond, A. (2013). Executive functions. Annual Review of Psychology, 64, 135-168. https://doi.org/10.1146/annurev-psych-113011143750 .

Downey, G., Lebolt, A., Rincón, C., \& Freitas, A. L. (1998). Rejection sensitivity and children's interpersonal difficulties. Child Development, 69, 1074-1091. https://doi.org/10.2307/1132363.

Dul, J., \& Ceylan, C. (2011). Work environments for employee creativity. Ergonomics, 54(1), 12-20. https://doi.org/10.1080/00140139.2010. 542833.

Dul, J., \& Ceylan, C. (2014). The impact of a creativity-supporting work environment on a firm's product innovation performance. Journal of Product Innovation Management, 31(6), 1254-1267. https://doi. org/10.1111/jpim.12149.

Fantini, M. P., Reno, C., Biserni, G. B., Savoia, E., \& Lanari, M. (2020). COVID-19 and the re-opening of schools: A policy maker's dilemma. Italian Journal of Pediatrics, 46(1), 1-3. https://doi.org/10. 1186/s13052-020-00844-1.

Faul, F., Erdfelder, E., Lang, A. G., \& Buchner, A. (2007). G* power 3: A flexible statistical power analysis program for the social, behavioral, and biomedical sciences. Behavior Research Methods, 39(2), 175 191. https://doi.org/10.3758/bf03193146.

Felipe, N. J., \& Sommer, R. (1966). Invasions of personal space. Social Problems, 14, 206-214. https://doi.org/10.1525/sp.1966.14.2. $03 \mathrm{a} 00080$.

Gremmen, M. C., van den Berg, Y. H., Segers, E., \& Cillessen, A. H. (2016). Considerations for classroom seating arrangements and the role of teacher characteristics and beliefs. Social Psychology of Education, 19(4), 749-774. https://doi.org/10.1007/s11218-0169353-y.

Guilford, J. P. (1956). The structure of intellect. Psychological Bulletin, 53(4), 267-293. https://doi.org/10.1037/h0040755.

Guilford, J. P. (1967). The nature of human intelligence. New York: McGraw-Hill. 
Haghighi, M. M., \& Jusan, M. M. (2012). Exploring students behavior on seating arrangements in learning environment: A review. ProcediaSocial and Behavioral Sciences, 36, 287-294. https://doi.org/10. 1016/j.sbspro.2012.03.032.

Hastings, N., \& Schwieso, J. (1995). Tasks and tables: The effects of seating arrangements on task engagement in primary classrooms. Educational Research, 37(3), 279-291. https://doi.org/10.1080/ 0013188950370306.

Hawkley, L. C., \& Cacioppo, J. T. (2010). Loneliness matters: A theoretical and empirical review of consequences and mechanisms. Annals of Behavioral Medicine, 40(2), 218-227. https://doi.org/10. 1007/s12160-010-9210-8.

Helton, W. S., Matthews, G., \& Warm, J. S. (2009). Stress state mediation between environmental variables and performance: The case of noise and vigilance. Acta Psychologica, 130(3), 204-213. https:// doi.org/10.1016/j.actpsy.2008.12.006.

Higgins, S., Hall, E., Wall, K., Woolner, P., \& McCaughey, C. (2005). The impact of school environments: A literature review. Retrieved from http://www.cfbt.com/PDF/91085.pdf

Kaitz, M., Bar-Haim, Y., Lehrer, M., \& Grossman, E. (2004). Adult attachment style and interpersonal distance. Attachment \& Human Development, 6, 285-304. https://doi.org/10.1080/ 14616730412331281520 .

Kaufman, A. S., \& Kaufman, N. L. (2004). Kaufman brief intelligence test. John Wiley \& Sons, Inc.

Lamm, H., \& Trommsdorff, G. (1973). Group versus individual performance on tasks requiring ideational proficiency (brainstorming): A review. European Journal of Social Psychology, 3(4), 361-388. https://doi.org/10.1002/ejsp.2420030402.

Lease, A. M., Kennedy, C. A., \& Axelrod, J. L. (2002). Children's social constructions of popularity. Social Development, 11(1), 87-109. https://doi.org/10.1111/1467-9507.00188.

Lipsitz, J. D., \& Schneier, F. R. (2000). Social phobia. Pharmacoeconomics, 18(1), 23-32. https://doi.org/10.2165/ 00019053-200018010-00003.

Maccoby, E. E. (1990). Gender and relationships: A developmental account. American Psychologist, 45(4), 513-520.

Manca, S., Cerina, V., Tobia, V., Sacchi, S., \& Fornara, F. (2020). The effect of school design on users' responses: a systematic review (2008-2017). Sustainability, 12(8), 3453. https://doi.org/10.3390/ su12083453

Marshall, P. D., \& Losonczy-Marshall, M. (2010). Classroom ecology: Relations between seating location, performance, and attendance. Psychological Reports, 107(2), 567-577. https://doi.org/10.2466/ 11.22.pr0.107.5.567-577.

Maxwell, L. E. (2003). Home and school density effects on elementary school children: The role of spatial density. Environment and Behavior, 35(4), 566-578. https://doi.org/10.1177/ 0013916503035004007.

McClure, E. B. (2000). A meta-analytic review of sex differences in facial expression processing and their development in infants, children, and adolescents. Psychological Bulletin, 126, 424-453. https://doi. org/10.1037//0033-2909.126.3.424

Mehrabian, A. (1968). Relationship of attitude to seated posture, orientation, and distance. Journal of Personality and Social Psychology, 10, 26-30. https://doi.org/10.1037/h0026384.

Meinel, M., Maier, L., Wagner, T., \& Voigt, K. I. (2017). Designing creativity-enhancing workspaces: A critical look at empirical evidence. Journal of technology and innovation management, 1(1), 1-12. Available at SSRN: https://ssrn.com/abstract $=3051058$

Milliken, F. J., Bartel, C. A., \& Kurtzberg, T. R. (2003). Diversity and creativity in work groups: A dynamic perspective on the affective and cognitive processes that link diversity and performance. In P. Paulus \& B. Nijstad (Eds.), Group creativity: Innovation through collaboration (pp. 32-62). New York: Oxford University Press. https://doi.org/10.1093/acprof:oso/9780195147308.003.0003.
MIUR (2020). School plan 2020-2021. Retrieved by: https://www.miur. gov.it/documents/20182/2467413/Le+linee+guida.pdf/4e4bb4111f90-9502-f01e-d8841a949429?version=1.0\&t=1593201965918.

Montoya, A. K., \& Hayes, A. F. (2017). Two-condition within-participant statistical mediation analysis: A path-analytic framework. Psychological Methods, 22(1), 6-27. https://doi.org/10.1037/ met0000086.

Nagar, D., \& Pandey, J. (1987). Affect and performance on cognitive task as a function of crowding and noise. Journal of Applied Social Psychology, 17(2), 147-157. https://doi.org/10.1111/j.1559-1816. 1987.tb00306.x.

Neill, S., \& Etheridge, R. (2008). Flexible learning spaces: The integration of pedagogy, physical design, and instructional technology. Marketing Education Review, 18(1), 47-53. https://doi.org/10. 1080/10528008.2008.11489024.

Newcomb, A. F., Bukowski, W. M., \& Pattee, L. (1993). Children's peer relations: A meta-analytic review of popular, rejected, neglected, controversial, and average sociometric status. Psychological Bulletin, 113(1), 99-128. https://doi.org/10.1037//0033-2909.113. 1.99 .

Norazman, N., Ismail, A. H., Ja'afar, N. H., Khoiry, M. A., \& Ani, A. I. C. (2019). A review of seating arrangements towards the $21^{\text {st }}$ century classroom approach in schools. Malaysian Journal of Sustainable Environment, 6(2), 21-46. https://doi.org/10.24191/ myse.v6i2.8684.

Pace, D., \& Price, M. (2005). Instructional techniques to facilitate inclusive education. In D. Schwartz (Ed.), Including children with special needs (pp. 115-131). Westport: Greenwood Press.

Paulus, P. B., \& Yang, H. C. (2000). Idea generation in groups: A basis for creativity in organizations. Organizational Behavior and Human Decision Processes, 82(1), 76-87. https://doi.org/10.1006/obhd. 2000.2888

Perkins, K. K., \& Wieman, C. E. (2005). The surprising impact of seat location on student performance. The Physics Teacher, 43(1), 30 33. https://doi.org/10.1142/9789812813787_0099.

Pichierri, M., \& Guido, G. (2016). When the row predicts the grade: Differences in marketing students' performance as a function of seating location. Learning and Individual Differences, 49, 437441. https://doi.org/10.1016/j.lindif.2016.04.007.

Rose-Krasnor, L. (1997). The nature of social competence: A theoretical review. Social Development, 6(1), 111-135. https://doi.org/10. 1111/1467-9507.00029.

Rothbart, M. K., Sheese, B. E., Rueda, M. R., \& Posner, M. I. (2011). Developing mechanisms of self-regulation in early life. Emotion Review, 3(2), 207-213. https://doi.org/10.1177/ 1754073910387943.

Rüstemli, A. (1992). Crowding effects of density and interpersonal distance. The Journal of Social Psychology, 132(1), 51-58. https://doi. org/10.1080/00224545.1992.9924687.

Steidle, A., \& Werth, L. (2013). Freedom from constraints: Darkness and dim illumination promote creativity. Journal of Environmental Psychology, 35, 67-80. https://doi.org/10.1016/j.jenvp.2013.05. 003.

Strayer, J., \& Roberts, W. (1997). Children's personal distance and their empathy: Indices of interpersonal closeness. International Journal of Behavioral Development, 20, 385-403. https://doi.org/10.1080/ 016502597385199.

Sundstrum, E., \& Altman, I. (1976). Interpersonal relationship and personal space: Research review and theoretical model. Human Ecology, 4, 47-67. https://doi.org/10.1007/bf01531456.

Szpak, A., Nicholls, M. E., Thomas, N. A., Laham, S. M., \& Loetscher, T. (2016). "No man is an island": Effects of interpersonal proximity on spatial attention. Cognitive Neuroscience, 7(1-4), 45-54. https:// doi.org/10.1080/17588928.2015.1048677.

Tobia, V., Riva, P., \& Caprin, C. (2017). Who are the children most vulnerable to social exclusion? The moderating role of self-esteem, 
popularity, and nonverbal intelligence on cognitive performance following social exclusion. Journal of abnormal child psychology, 45(4), 789-801. https://doi.org/10.1007/s10802-016-0191-3

UNSESCO (2020). COVID-19 Impact on Education. Retrieved by https://en.unesco.org/covid19/educationresponse

van den Berg, Y. H., \& Cillessen, A. H. (2015). Peer status and classroom seating arrangements: A social relations analysis. Journal of Experimental Child Psychology, 130, 19-34. https://doi.org/10. 1016/j.jecp.2014.09.007.

van den Berg, Y. H., Segers, E., \& Cillessen, A. H. (2012). Changing peer perceptions and victimization through classroom arrangements: A field experiment. Journal of Abnormal Child Psychology, 40(3), 403-412. https://doi.org/10.1007/s10802-011-9567-6.
Varni, J. W., Limbers, C. A., \& Burwinkle, T. M. (2007). Parent proxyreport of their children's health-related quality of life: An analysis of 13,878 parents' reliability and validity across age subgroups using the PedsQL ${ }^{\mathrm{TM}} 4.0$ generic Core scales. Health and Quality of Life Outcomes, 5(1), 2. https://doi.org/10.1186/1477-7525-5-2.

Wannarka, R., \& Ruhl, K. (2008). Seating arrangements that promote positive academic and behavioural outcomes: A review of empirical research. Support for Learning, 23(2), 89-93. https://doi.org/10. 1111/j.1467-9604.2008.00375.x.

Publisher's Note Springer Nature remains neutral with regard to jurisdictional claims in published maps and institutional affiliations. 